\title{
A Geophysical Investigation for Subsurface Characterization and Structural failure at the Site of a Building, Southwestern Nigeria
}

\author{
${ }^{1,3}$ Ibitoye, F. P., ${ }^{1}$ J. S. Ojo, ${ }^{1}$ O. J. Akintorinwa, ${ }^{2}$ M. O. Olorunfemi, ${ }^{2}$ A. A. \\ Adepelumi, ${ }^{3,4}$ K. J. Akinluwade, ${ }^{3}$ A. T. Taiwo, ${ }^{3}$ D. A. Isadare and \\ ${ }^{3,5}$ A. R. Adetunji \\ ${ }^{I}$ (Department of Applied Geophysics, Federal University of Technology, Akure, Nigeria) \\ ${ }^{2}$ (Department of Geology, Obafemi Awolowo University, Ile - Ife, Nigeria) \\ ${ }^{3}$ (Prototype Engineering Development Institute, Ilesa, Nigeria) \\ [National Agency for Science and Engineering Infrastructure] \\ ${ }^{4}$ (Department of Materials Science and Engineering, African University of Science and Technology (AUST), \\ Abuja, Nigeria) \\ ${ }^{5}$ (Department of Materials Science and Engineering,Obafemi Awolowo University, Ile - Ife, Nigeria)
}

\begin{abstract}
This study reports a geophysical survey involving the electrical resistivity method utilizing the Vertical Electrical Sounding (VES) and Electrical Imaging techniques conducted around the distressed walls of a School building with the aim of studying the causes of distress in the walls and characterizing the soil conditions of the area. A total of 20 Vertical Electrical Sounding (VES) stations were occupied using Schlumberger Configuration with $A B / 2$ varying from 1 to $65 \mathrm{~m}$. In the electrical imaging, dipole-dipole array was adopted and the two traverses were occupied in the $S-N$ and $E-W$ directions close to where the wall cracks were manifested. Four geoelectric sequences were delineated within the study area. These include the topsoil, weathered layer, partially weathered/fractured basement and fresh basement. Two linear features (suspected fault) were identified by the electrical imaging on bedrock along the $S-N$ direction. Results identified differential settlement resulting from incompetent subsoil materials and faulted bedrock as possible failure cause.
\end{abstract}

Keywords: Foundation, migmatite, faulted bedrock, fractures, structure

\section{INTRODUCTION}

Geotechnical engineering practices require investigations of the soil and the subsurface at sites chosen for engineering constructions. This is routinely done to ascertain the suitability of the earth materials at such sites for proposed structures i.e. in terms of bearing capacity and/or hosting fitness. In baseline studies for pipelaying programmes, for example, issues relating to the corrosivity of host soil, alongside with possible effects of leakages along the pipeline route are investigated [1].

Also, in landfill projects, the ability of the host rocks to prevent leachates from finding their way into the aquifer system is given top priority [2]. The bearing capacity of rocks in relation to vehicular traffic is reckoned with in road construction projects.

In spite of this obvious necessity, site engineers for reasons of cost and other considerations like assumptions in structural design, sometimes fails to incorporate pre-construction investigations in their job schedule. At times, in cases where such studies have been carried out, the findings are not taken into account in design and construction phases. The result of this omission is usually failed structures [3,4].

In order to ascertain the causes of such failure, which manifests as ground subsidence, major cracks and dislocation of the walls of a school building in south-western Nigeria (Fig. 1), a geophysical investigation involving the electrical resistivity method was therefore carried out with the aim of delineating geoelectric layer and their geoelectric parameters, mapping the soil corrosivity and identifying possible geologic structures such as fractures and faults that may be responsible for the structural failure of the building.

Since the electrical resistivity of earth materials can be influenced by parameters such as rock matrix, porosity, permeability, temperature, degree of fracturing, grain size, rock type and the extent of weathering. The electrical resistivity method is therefore adopted for this research.

\section{THE STUDY AREA}

The study area (Fig. 2) expressed in the Universal Traverse Mercator (UTM) coordinates of Zone 31 , is located within northings $80275 \mathrm{mN}$ and $807360 \mathrm{mN}$ and eastings $735932 \mathrm{mE}$ and $736045 \mathrm{mE}$.

The topography of the study area is characterized by varying elevation above the sea level and undulating relief. The study area is surrounded by ever green vegetation. The area lies within the tropical rain forest climate region of Nigeria. It is characterized by two distinct seasons, the wet season (between April and 
October) and the dry season (between November and March). The annual rainfall is about $1600 \mathrm{~mm}$, while the average daily temperature is $29^{\circ} \mathrm{C}$. The study area is underlain by gneiss migmatite. The campus is underlain by the rocks of the Precambrian Basement complex of the southwestern Nigeria [5]. The crystalline rocks include the granites, biotite gneiss, charnockite and quartzite. (Fig. 3). Pavement outcrops of the biotite gneiss occur in several locations within the campus.

In other parts of the campus, charnockite occur as discrete bodies; granite occurs as intrusion within the biotite gneiss. The geology and boundaries of the lithological units were however inferred in places where they are concealed by superficial residual soil [6].
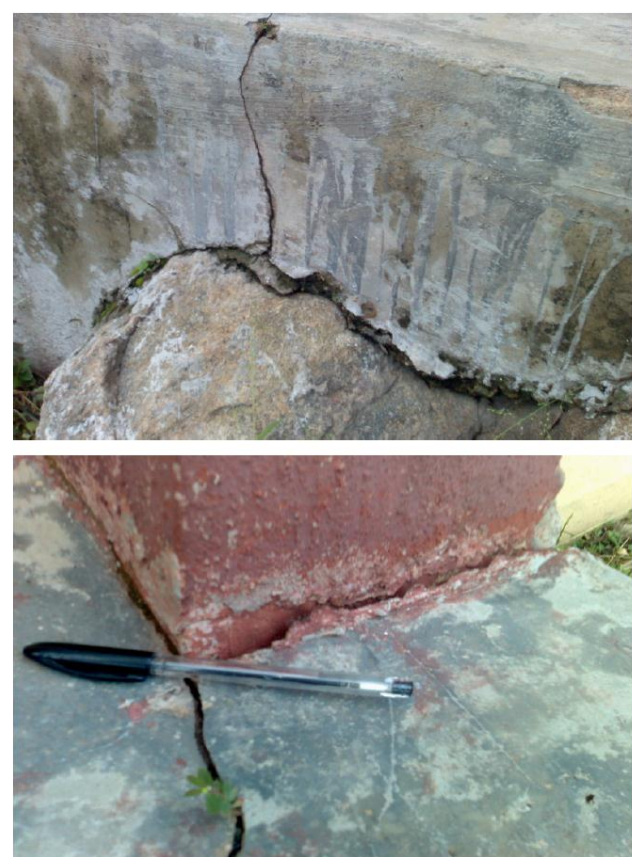

Figure 1: Surface expression of the bedrock and effects on a major pillar

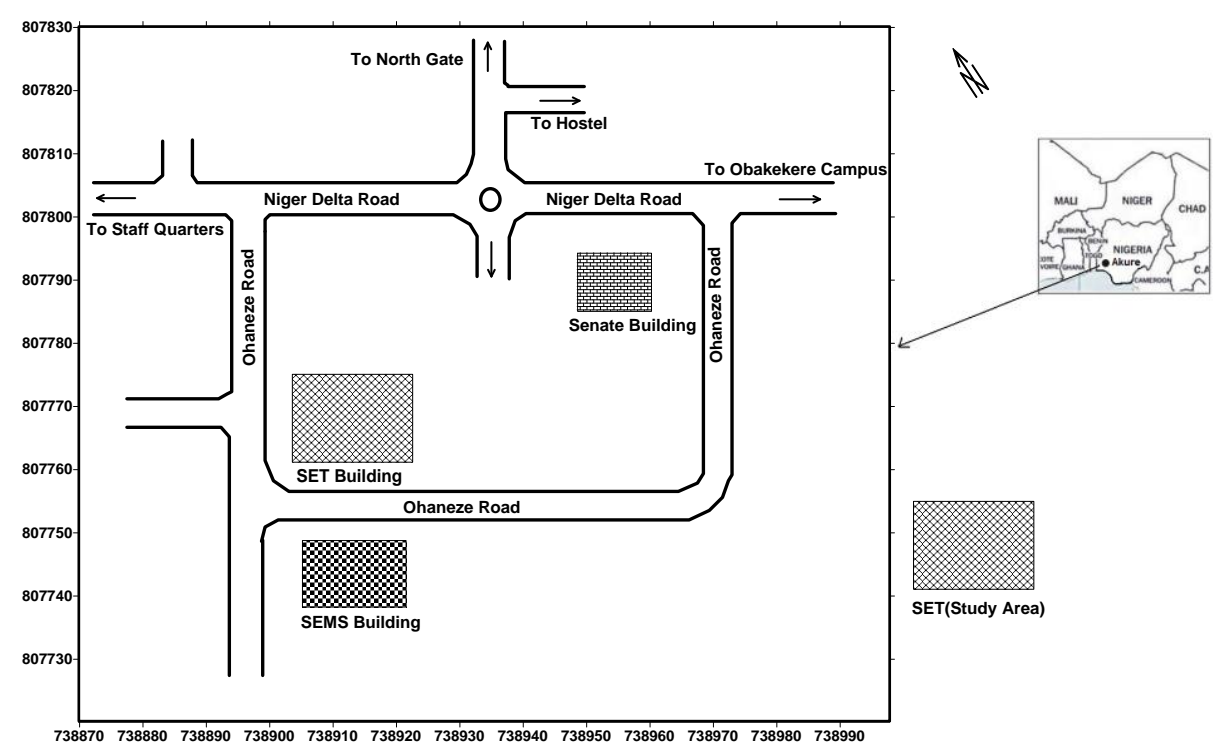

Figure 2: Sketch map of the school campus showing the Study Area 


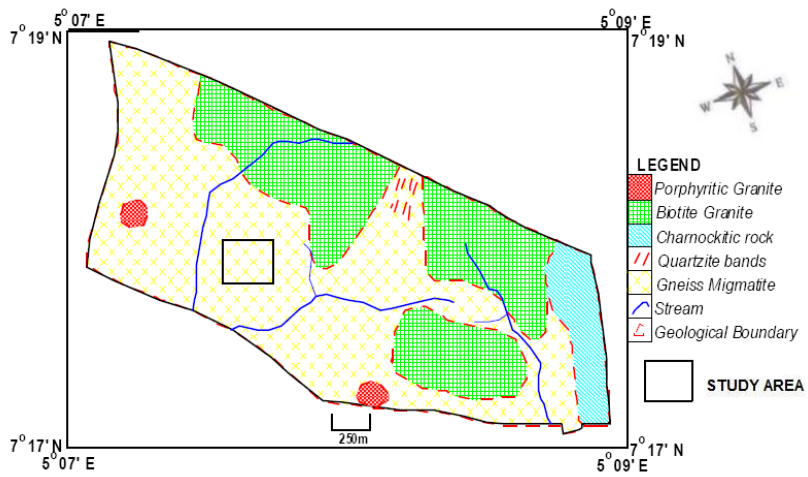

Figure 3: Geological Map of extended area around school campus [6].

\section{THE GEOPHYSICAL SURVEY}

Electrical resistivity method using Schlumberger vertical electrical sounding and combined horizontal profiling and vertical electrical sounding was employed in data collection.

Two traverses were established at the western parts while three traverses were established at the northern parts of the study building (Fig. 3). Four VES stations were occupied along each of the two traverses that run S-N which were located at the western side of the investigated building. Four VES stations were occupied along each of the three traverses that run E-W which were located at the northern side of the building. The traverse lengths varied from $45 \mathrm{~m}$ to $95 \mathrm{~m}$ while the traverse-traverse separation is $5 \mathrm{~m}$. The locations of the VES points were constrained by the manifestation of failure on the walls.

Twenty (20) vertical electrical soundings (Four per traverse) were conducted within the study area using an Ohmega resistivity Terrameter. Schlumberger array was employed with electrode separations $(A B / 2)$ ranging from 1 to $65 \mathrm{~m}$. The location of each of the sounding station was recorded in Universal Traverse Mercator (UTM) Zone 31 coordinates with the aid of a GARMIN 12 channel personal navigator (GPS) unit. The results of the curve matching (layer resistivities and thicknesses) were fed into the computer as a starting model in an iterative forward modelling technique using Win RESIST version 1.0 [7]. From the results (layer resistivities and thicknesses), five geoelectric sections along E-W and S-N directions were produced, and results were also used to generate layer parameter histograms.

For the combined horizontal profiling and vertical electrical sounding as sounding technique, the same traverses where VES were carried out, were also used. The dipole-dipole array was used for the data acquisition. The inter-electrode spacing of $5 \mathrm{~m}$ was adopted while inter-dipole separation factor (n) was varied from 1-5. The apparent resistivity values were calculated using $\pi a(n+1)(n+2) n$ as the geometric factor. 2-D inversion modeling of the Dipole-Dipole data was carried out using DIPRO ${ }^{\mathrm{TM}}$ Software developed by the Korea Institute of Geoscience and Mineral Resources [8].

\section{RESULTS AND DISCUSSIONS}

The results of this research work are presented as field curves, histograms, geoelectric sections, pseudosections and 2-D inversion models.

\subsection{Field Curves}

The curves types identified within the study area range from $\mathbf{A}, \mathbf{H}$ and $\mathbf{A A}$. The number of layers varies between 3-layers and 4-layers. A curve is the predominant one (Fig. 5), constituting 70\% of the total, while the $\mathbf{H}$ and AA types constitute 25\% and 5\% respectively. Typical curve types in the area are shown in Figure 6a-c. The implication of ' $\mathbf{A}$ ' curve type as the predominant curve in the area is that the bedrock is generally shallow within the area.

\subsection{Geoelectric characteristics}

The VES interpretation results were used to prepare 2-D geoelectric sections along two directions; S-N and E-W directions. Figs. 7 and 8.

The geoelectric section along S-N direction (Fig. 7) identified four geoelectric/geologic subsurface layers comprising the clay/sandy clay topsoil (resistivity varies from 60 to $125 \mathrm{ohm}-\mathrm{m}$ and thickness ranges from $0.6 \mathrm{~m}-1.4 \mathrm{~m}$ ); clay/sandy clay weathered layer (resistivity varies from 45 to $201 \mathrm{ohm}-\mathrm{m}$ and thickness ranges from $1.5 \mathrm{~m}-2.8 \mathrm{~m}$ ); fractured basement beneath VES 1 (resistivity of $328 \mathrm{ohm}-\mathrm{m}$ and thickness of $14.2 \mathrm{~m}$ ) and fresh basement (resistivity varies from 446 to $896 \mathrm{ohm}-\mathrm{m}$ ). 


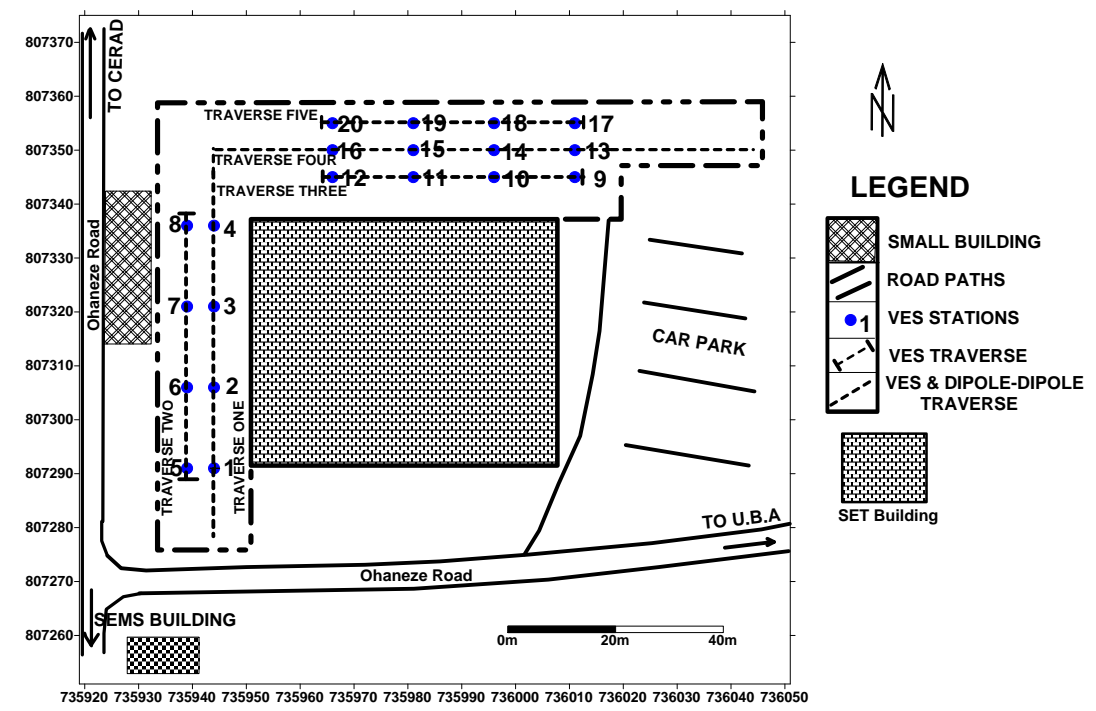

Figure 4: Geophysical Data Acquisition Map of the Site.

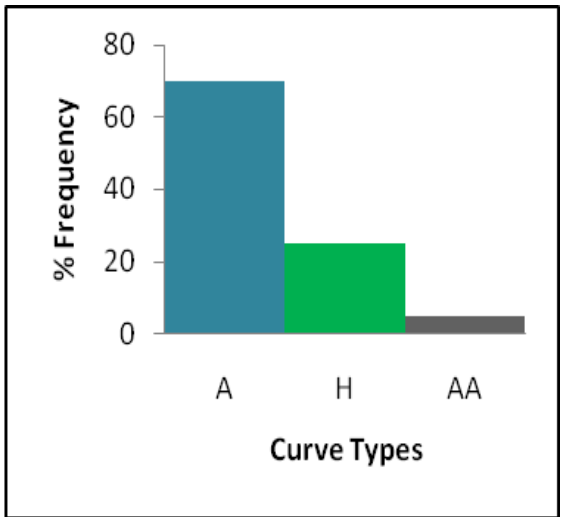

Figure 5: Histogram of the VES curve types in the study area

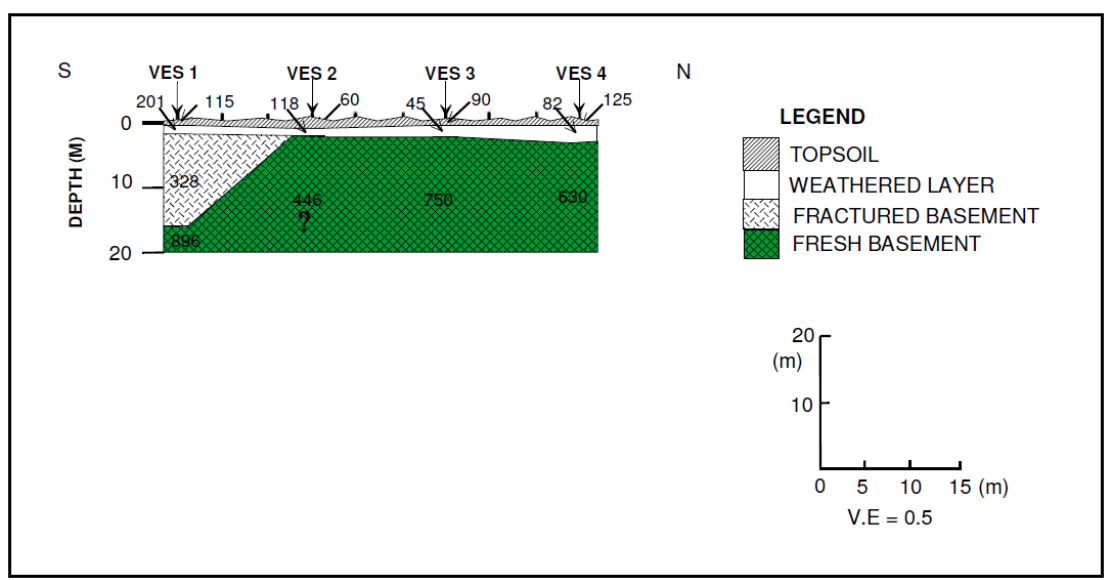

Figure 6: Typical sounding curves in the study area showing (a) A Type (b) H Type (c) AA Type 

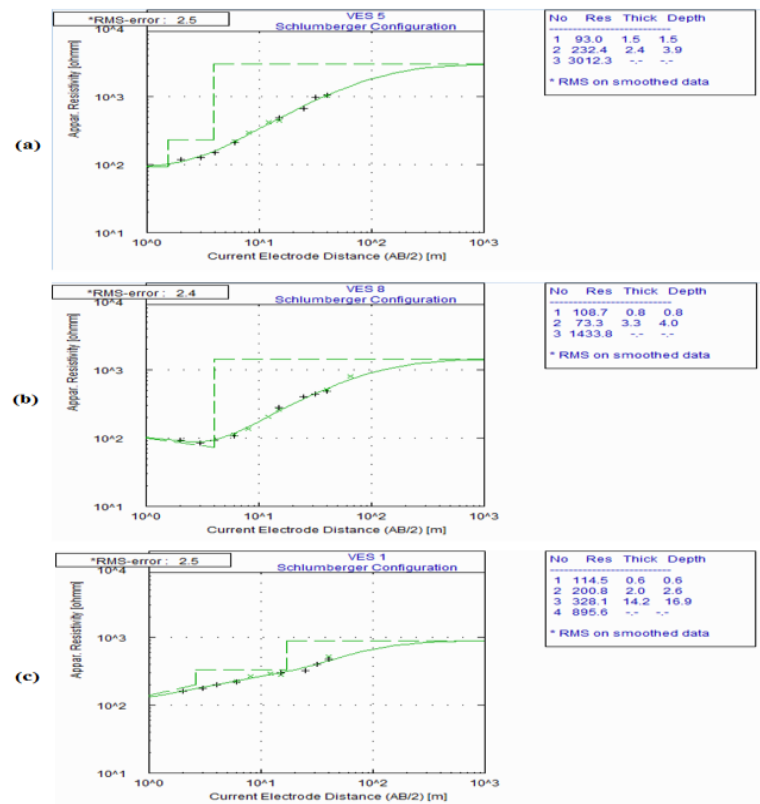

Figure 7: Geoelectric Section along S-N Direction.

The depth to rock head ranges from $2.9 \mathrm{~m}$ to $3.4 \mathrm{~m}$. The overburden is generally thin but thinnest at VES 2 (2.9m) and thickest at VES $4(3.4 \mathrm{~m})$ at the southern flank.

The geoelectric section along E-W direction (Fig. 8) identified three geoelectric/geologic subsurface layers comprising the clay/sandy clay topsoil (resistivity varies from $62 \mathrm{ohm}-\mathrm{m}$ to $115 \mathrm{ohm}-\mathrm{m}$ and thickness ranges from 0.6$1.5 \mathrm{~m}$ ); sandy clay/clayey sand weathered layer (resistivity varies from 127 to $201 \mathrm{ohm}-\mathrm{m}$ and thickness ranges from 1.5$2.6 \mathrm{~m}$ ) and fresh basement (resistivity varies from 1262 to $3020 \mathrm{ohm}-\mathrm{m}$ ).

The depth to rock head ranges from $2.4 \mathrm{~m}$ to $4.1 \mathrm{~m}$. The overburden is also generally thin but thinnest at VES 15 $(2.4 \mathrm{~m})$ and thickest at VES $16(4.1 \mathrm{~m})$, The bedrock relief gently dips down towards eastern flank (Left end), except for the significant basement depression noticed at VES 16 on the western flank (Right end).

Results of the field curves and geoelectric sections generally indicate three main geoelectric layers, namely the topsoil, the weathered layer and the fresh basement, the fractured basement is only localised at VES 1 . The topsoil generally varies in composition from clay to sandy clay, but predominantly composed of clay formation with resistivity values generally less than $100 \mathrm{ohm}-\mathrm{m}$. The topsoil is generally thin, with the thickness in the range of $0.41-0.60 \mathrm{~m}$ as the predominant thickness. The weathered layer is predominantly composed of clay formation with resistivity values in the range of $100-200 \mathrm{ohm}-\mathrm{m}$. The mean resistivity value is $157 \mathrm{ohm}-\mathrm{m}$. The thickness of this layer ranges from $0.6 \mathrm{~m}$ to $4 \mathrm{~m}$ with a mean value of $2.2 \mathrm{~m}$.

The resistivity of the fresh basement ranges from 357-3716ohm-m with a mean value of $1462 \mathrm{ohm}-\mathrm{m}$. The depth to fresh bedrock (overburden thickness) ranges from $1.2 \mathrm{~m}$ to $16.9 \mathrm{~m}$ with a mean value of $3.8 \mathrm{~m}$. The highest depth to fresh bedrock was noticed at VES 1 while the lowest was noticed at VES 9.

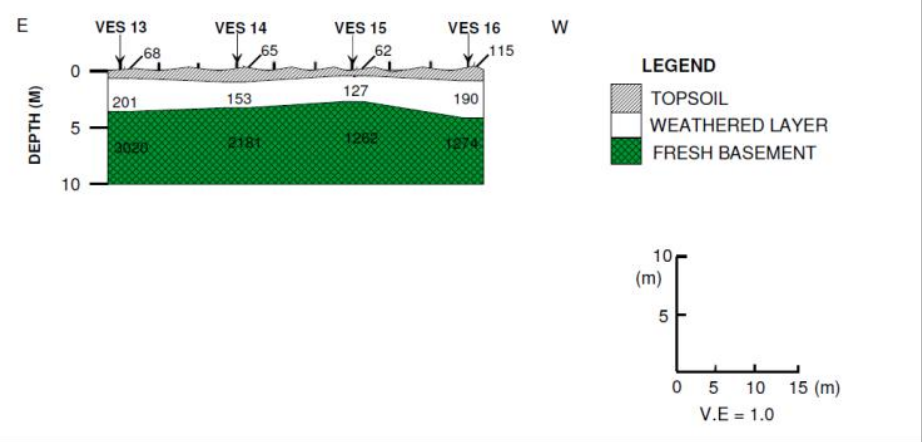

\subsection{Combined Horizor}

Figure 8: Geoelectric Section along E-W Direction

The Dipole-Dipole pseudosections and the 2-D resistivity structure along S-N direction are shown in Fig. 9. The 2D resistivity structure revealed three geologic layers; topsoil (blue colour), weathered layer (green colour) and the fresh basement rock (yellow and purple colour). The topsoil was subsumed into the weathered layer in many places due to its thickness. The bedrock was outcrop between stations 2 and 7. The bedrock shows two vertical discontinuities that are typical of linear structures along the S-N direction. The linear features are located between stations 7 and 10 and stations 12 and 14 . The suspected linear structures are of significant depth extent $(>5 \mathrm{~m})$. The low resistivity zone between stations 7-10 (35- 
$50 \mathrm{~m}$ ) could be diagnostic of a suspected fault zone with a width of approximately $9 \mathrm{~m}$. The suspected fault zone falls within the extremely failed segment of the investigated building. The uneven nature of the bedrock was also revealed by the 2-D resistivity structure.

Fig. 10 shows the Dipole-Dipole pseudosection (field and theoretical data) and 2-D resistivity structure along E-W direction. Three geologic layers were delineated by the resistivity structure. This includes topsoil (blue colour) which only appears between stations 2 and 5 and subsume into weathered layer along other stations due to its thinness; the weathered layer (green) and the basement bedrock. The relatively uneven nature of the bedrock along this direction is also revealed by the 2-D resistivity structure. There is no evidence of discontinuity within the bedrock typical of suspected fault.

\subsection{Correlation of Results}

Along S-N direction traverse, both the topsoil and the weathered layer in the upper 0-2m are clayey (Fig. 11a and b). The basement relief is uneven and outcrop between stations 2 and 7 (Fig 11b). Both the geoelectric section (Fig. 11a) and the 2-D resistivity structure (Fig. 11b) shows that the basements are shallow along this direction. The identified linear feature between stations 7 and 10 (Suspected fault) (Fig. 11b) correlated with where a basement fracture is delineated by the geoelectric section (Fig.11a).

The correlation of the geoelectric section and the 2-D resistivity along E-W direction are shown in Fig.12 (a and b). The upper 0-4m composed of clay/sandy clay/clayey sand, which are characterised by low resistivity values (Fig. 12a and b). The basement topography along the E-W direction is relatively even (Fig. 12a and b). The featurelessness (structurally) of the 2-D resistivity structure (Fig. 12b) are indications of a near homogeneous subsurface sequence (Fig 12a).

\subsection{Sub-soil evaluation of the study area}

From the geophysical results obtained from the study site, it was confirmed that the topsoil and weathered layer varies in composition from clay to sandy clay, but predominantly composed of sandy clay with a mean resistivity value of 130 ohm-m.

The average resistivity value falls within $100-350 \mathrm{ohm}-\mathrm{m}$ ranges of resistivity values and can therefore be regarded as moderately competent, but for the higher clay to sand ratio $(130 \mathrm{ohm}-\mathrm{m})$ and thinness nature of this formation (generally less than $2.5 \mathrm{~m}$ ), the foundation of this structure is not expected to be hosted within this formation but on the top of the fresh bedrock. Due to the presence of linear feature (Suspected fault) which acts as a weak zone within this basement rock, it is not expected to be able to host a civil structure without the manifestation of differential settlement which will later show at the surface as cracks in the erected walls.

s
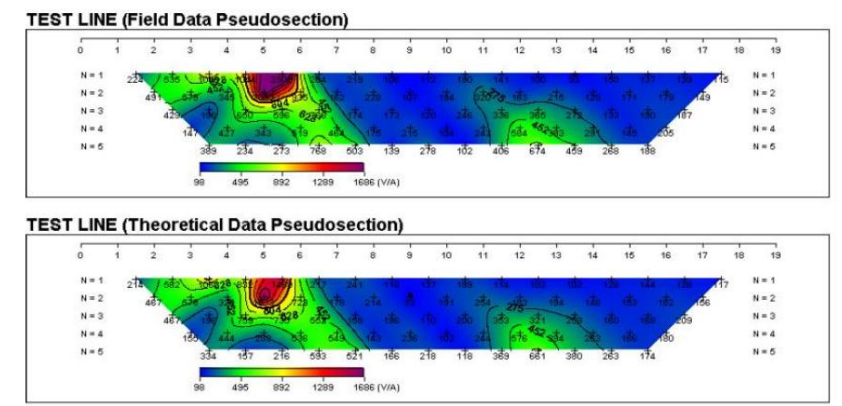

TEST LINE (2-D Resistivity Structure)

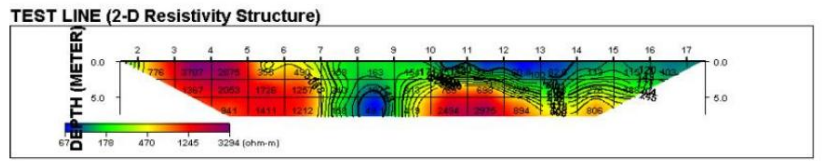

Figure 9: 2-D Modeling of Dipole-dipole along S-N Direction
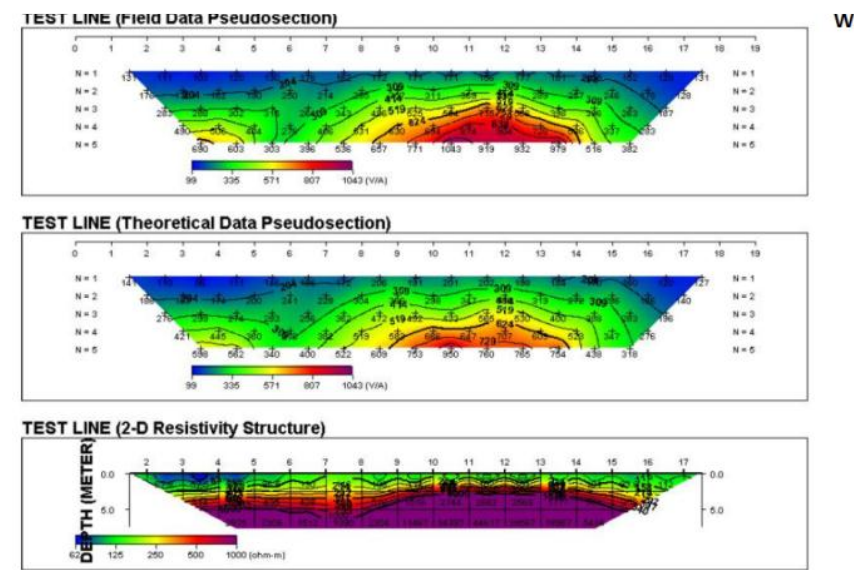

Figure 10: 2-D Modeling of Dipole-dipole along E-W Direction 


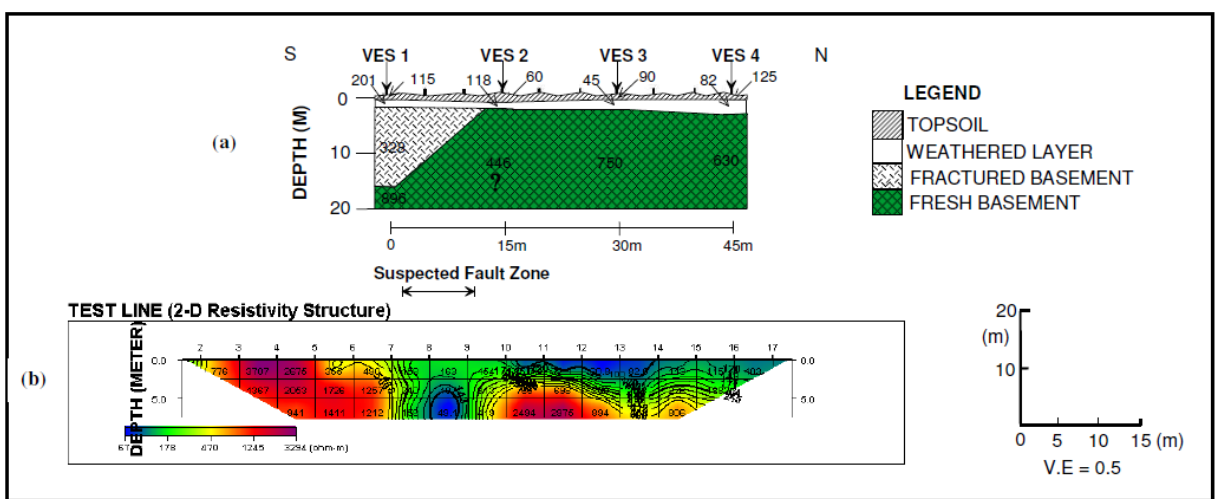

Figure 11: Correlation of Geoelectric Section and 2-D resistivity structure along S-N Direction

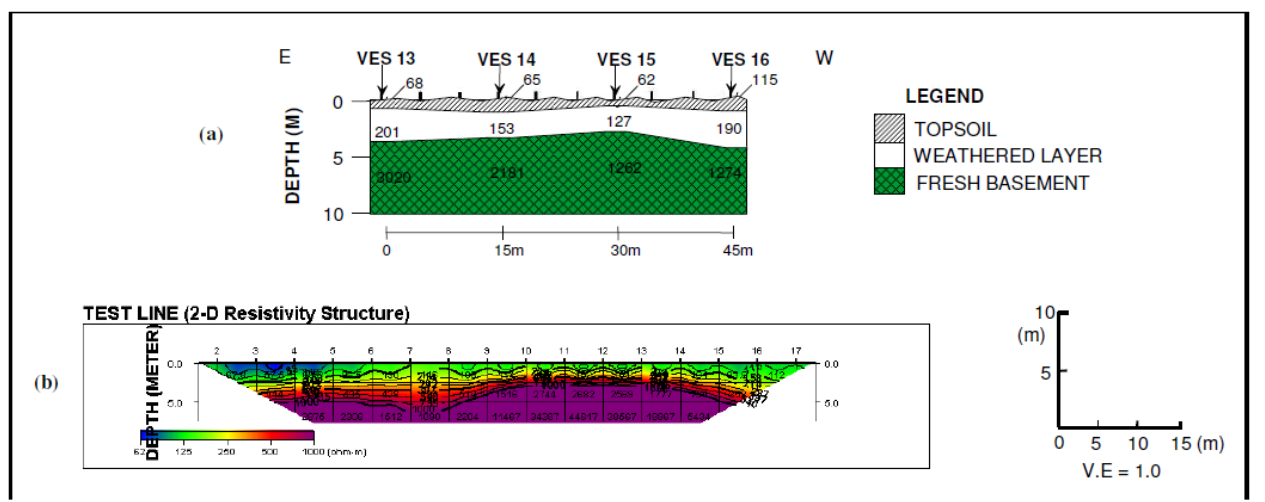

Figure 12: Correlation of Geoelectric Section and 2-D resistivitv structure along E-W Direction.

\section{CONCLUSIONS}

The following conclusions were drawn from the investigation:

(i) Four geoelectric sequences were delineated within the study area. These include the topsoil, weathered layer, partially weathered/fractured basement and fresh basement. The topsoil and weathered layer are composed of clay/sandy clay formation and the bedrock is generally shallow (less than $3 \mathrm{~m}$ ).

(ii) Two linear features (Suspected fault) were identified by the electrical imaging on bedrock along the S-N direction. This may have been the reason for the cracking of the building walls along this direction, since it was suspected that the foundation of the structure was placed on this weak bedrock.

(iii) The upper $2 \mathrm{~m}$ in the area where metallic objects can be buried is clayey in nature; hence any metallic object buried within this area without proper protection may be threatened by corrosion. This clayey nature of the upper soil makes the area a good earthing medium.

(iv) The causes of the distress in the walls of the investigated building may not be due to substandard building material or construction practice, but it may have been influenced by the differential settlement resulting from the incompetent subsoil materials and the faulted bedrock on which the foundation of the building was built upon.

(v) The importance of pre-geophysical investigation of a proposed civil structure cannot be overemphasized, since this will help in designing of such structures in order to withstand the test of time.

\section{REFERENCES}

[1] Agunloye, O., 1984, Soil Aggresivity along Steel Pipeline Routes at Ajaokuta: Journal of Mining and Geology, Vol. 21, pp 97-101.

[2] Barker, R.D., 1999, Surface and borehole geophysics. In: Lloyd JW (ed) Hardrock aquifers. UNESCO, Paris.

[3] Olorunfemi, M.O.; Ojo, J.S.; Sonuga, F.A.; Ajayi, O.; and Oladapo, M.I.,2000, Geoelectric and electromagnetic investigation of the failed Koza and Nassarawa earth dams around Katsina, northern Nigeria: Journal of Mining and Geology, Vol. 36, No. 1, pp. 51-65.

[4] Olorunfemi, M.O.; Idornigie, A.I.; Fagunloye, H.O.; and Ogun, O.A, 2004, Assessment of Anomalous Seepage Conditions in the Opa Dam Embankment, Ile-Ife, South Western Nigeria: Global Journal of Geological Science, Vol. 2, No.2, pp.191-198.

[5] Rahaman, M.A., 1976, Review of the basement geology of southwestern Nigeria. Geology of Nigeria, pp. 41-58.

[6] Kareem, 1997, Updated Geologic map of Federal University of Technology, Akure, Ondo State.

[7] Vander Velpen, B.P.A.,1998, Resist version 1.0 Msc Research project, ITC., Netherlands.

[8] KIGAM, 2001, DIPRO version 4.01, Processing and interpretation software for electrical resistivity data. KIGAM, Daejeon, South Korea 